\title{
Intergenerational relations: the use of technology as a mediator
}

\author{
RAYMUNDO, T. M., BERNARDES, M. S., SANTANA, C. S. \\ Interunits Post Graduate Program in Bioengineering University of Sao Paulo - Brazil \\ 3900 Bandeirantes Avenue \\ Interunits Post Graduate Program in Bioengineering University of Sao Paulo - Brazil \\ 3900 Bandeirantes Avenue \\ Ribeirão Preto Medical School, University of Sao Paulo \\ 3900 Bandeirantes Avenue
}

\begin{abstract}
The social dynamics of today provide greater proximity between people belonging to different generations, diluting the differences among the large volume of innovations, whether technological or cultural that are produced continuously'. Intergenerational relationships can bring great benefits to the young and older, who may learn together through their experience, the mutual exchange of knowledge or merely for the daily contact ${ }^{2}$. Goal: Understanding how young monitors participants of a digital inclusion project for seniors (PIDI) relate to the elderly, which are the benefits of this relationship and the changes it brings in the life and family environment of these young people. Method: This is a qualitative, crosssectional and descriptive study. Data collection was conducted through a questionnaire with open questions. The responses were analyzed and grouped according to their content. Results: 16 monitors who participated in the PIDI took part in this study (students with scholarship and volunteers), of which $69 \%$ are women and $31 \%$ are men, with an average age of 25 . Regarding the time of participation in the project, $44 \%$ attended for six months, $25 \%$ for a year and $31 \%$ more than one year. $62.5 \%$ of them considered the relationship with the elderly as excellent and $37.5 \%$ considered as good. The monitors report that the process of teaching the elderly is facilitated due to the fact that the elderly are willing to learn and that the relationship established in this process is very natural. According to the monitors, the elderly are understandable and have patience forward to exchanging roles in which the young are teaching the older. The monitors also report that they learned to be more patient, be aware of difficulties, be more caring, respect differences, to listen more, to recognize specific characteristics of the elderly, in addition to personal growth. Young people report that they were able to transfer what they have learned in the relationship with the elderly for their family environment reporting that they began to act with more patience and tolerance, now have a closer interaction with elderly relatives, and better understand their difficulties and recognize their potential and, they start to assist and teach family members in the use of electronic devices. Conclusion: The intergenerational interaction is a valuable tool to exclude preconceptions, for the transfer of knowledge, mutual aid, solidarity and friendship.
\end{abstract}

\section{Indexing terms/Keywords}

Intergenerational relationships; Elderly; Technology

\section{Academic Discipline And Sub-Disciplines}

Gerontology; Gerontechnology;

\section{SUBJECT CLASSIFICATION}

Intergenerational relations

\section{TYPE (METHOD/APPROACH)}

qualitative, cross-sectional and descriptive study

\section{Council for Innovative Research}

\author{
Peer Review Research Publishing System
}

\section{Journal: INTERNATIONAL JOURNAL OF COMPUTERS \& TECHNOLOGY}

Vol. 14, No.10

www.ijctonline.com, editorijctonline@gmail.com 


\section{INTRODUCTION}

Aging is a universal and diverse phenomenon, and although life expectancy is higher in North America and Europe countries and Japan, the largest number of elderly people is concentrated in developing countries, including India, and South American countries (Holtz, 2008).

As a developing country, Brazil has experienced rapid growth in its elderly population, which is a process that is expected to intensify in the coming decades. This projection was made based in reducing fertility rates, common in Brazil and in the decreasing mortality of older age groups (IBGE, 2008; Zanon, Moretto, \& Rodrigues, 2013).

The longevity, theme increasingly present in our society, has led to important changes in family structure, which results in the possibility of lasting interaction between different generations, such as great-grandparents, grandparents, children and grandchildren living simultaneously. Therefore, studies on intergenerational relations has gained ground in the scientific field, giving focus on three main pillars, including: intergenerational transmission, with regard to culture and behaviour; intergenerational perception, related to the similarities and differences between the generations; and intergenerational solidarity, referring to the bond characteristics established between individuals (Vicente \& Souza, 2012).

Through interactions and through the exchange of experiences on generational identity process, young and old have improved their understanding and vision of the other, because there is an effective exchange of knowledge, values and care activities between the two groups (Schmidt, 2007; Souza, 2003).

In fact, the intergenerational relationship is present in everyday life and this does not occur only within the family environment, but also extends to social institutions, health and education through the exchange of knowledge. Elderly transmit knowledge through their wisdom gained through life, opportunities and life experience, while younger people have the knowledge about the changes of modern life, which contributes to (re) define the knowledge of old and insert it in contemporary times. It is this sharing that make them belong the same society and the same time (Gvozd \& Dellaroza, 2012).

Intergenerational exchanges and the sense of belonging to society are closely related to quality of life, because it refers to the active participation in the contexts of life as opposed to social isolation. For the World Health Organization (1994), the quality of life with is related to the perception of the subject as to their position in life, their values, culture and future expectations. It is therefore necessary to provide educational, economic, health and social benefits for the inclusion and for good relationships between different generations.

Promoting a good quality of life in old age exceeds the limits of personal responsibility and should be taken into account as a socio-cultural enterprise. Thus, a satisfactory aging is not only an attribute of the biological, psychological or social individual, but also the quality of the interaction between people from different generations (Neri, 1993).

Some social problems faced in the world of today can enable the intergenerational relationship, such as technological advances and the resulting digital exclusion of elderly population. We now live in an era of rapid development of electronic devices, especially those related to information and communication technologies such as mobile phones, tablets, computers, among others.

The embarrassment of the elderly in the use of these technologies is a reality that can be modified through the help of the younger generations, who are holders of knowledge and management of these devices. Digital inclusion generates a more effective participation for those who take ownership of it, promoting citizenship and the rescue of the social role (Meirelles, et al., 2014).

It must be considered that the intergenerational interaction serves as a potentiating tool to increase the sense of selfefficacy, changing preconceived ideas about aging as a phase of limitations and disabilities, as well as a stimulating source of the desire to live fully in the cultural and social context and thus contributing to the maintenance of quality of life (Godfarb \& Lopes, 2006).

Therefore, this study aimed to describe how young participants of a digital inclusion project for elderly understand the intergenerational relationship and the specifics of the aging process in their academic and familiar environment.

The hypothesis is that living with elderly and teaching gives young people an awareness about the physiological, cognitive, and social issues of aging and provides a transfer of the benefits of relations with the older to the familiar environment of these students.

\section{METHOD AND MATERIALS}

This is a qualitative and quantitative study, transversal and descriptive, conducted by the university extension project entitled "Digital Inclusion Project for the Elderly (PIDI)" which belongs to Ribeirao Preto Medical School - University of Sao Paulo, Brazil.

PIDI was created in 2010 and since this year has attended more than 450 seniors in the city of Ribeirao Preto and region. This project aims to help older people for independent use of electronic equipment in the everyday life. Specifically seeks to introduce and expand knowledge of equipment and technologies such as computer and internet, mobile phone, remote control, camera, and other devices. Classes are taught by graduate students and postgraduate provided or volunteers. The students who receive scholarship remain on the project for at least one year and, for the volunteers, there is no preset time of permanence in the project. 
Through the actions developed in the project it is possible for students to develop skills and competencies to work with the elderly in the creation of strategies and resources that enable learning through intergenerational relationship.

The sample included 16 students who participated in the PIDI between the years 2010 and 2015. Data collection was performed by applying a questionnaire already used in PIDI as a means of assessing the activities of the project and participation of students. The questionnaire contains 11 discursive questions about the perception of student monitors in relation to the work specificities with elderlies, the benefits and learnings resulting from this relationship and the possibility of transfering the knowledge acquired in the project through intergenerational relationship for their family environment.

Data were grouped for analysis according to its contents.

\section{RESULTS AND DISCUSSION}

The study included 16 students, 11 women (69\%) and 5 men (31\%), with an average age of 25 (table 1).

Table 1. Sample characterization and participation time in PIDI

\begin{tabular}{|l|c|c|}
\hline Gender & $\mathbf{n}$ & $\%$ \\
\hline Female & 11 & $69 \%$ \\
\hline Male & 5 & $31 \%$ \\
\hline Education & $\mathbf{n}$ & $\%$ \\
\hline Undergraduate students & 5 & $69 \%$ \\
\hline Postgraduate students & $\mathbf{n}$ & $31 \%$ \\
\hline Type of participation in the PIDI & 10 & $\%$ \\
\hline Fellows & 6 & $63 \%$ \\
\hline Volunteers & $\mathbf{n}$ & $37 \%$ \\
\hline Time of participation in the PIDI & 7 & $44 \%$ \\
\hline Until six months & 4 & $25 \%$ \\
\hline Until one year & 5 & $31 \%$ \\
\hline More than one year & & $\%$ \\
\hline
\end{tabular}

When asked to evaluate the relationships developed with the elderly during the participating in the project, $62.5 \%$ of the monitors consider it as excellent and $37.5 \%$ as good. The more balanced and enjoyable are the relations of exchanges among young people and the elderly, the greater the physical and psychological benefits for both, fostering socio-cultural development of both generations through mutual coeducation. The possibility of rapprochement between the groups provides a realistic view about youth and elder, minimizing the effects of the preconception and age segregation (Ramos, 2002; Santana, Pereira, 2012).

Ferrigno (2006) says in his studies that the exchange of experiences act as a break of intergenerational barriers. Through these exchanges, the elderly can find a space to express themselves and thus can find answers to contemporaneous issues. And the younger start to cultivate a culture of tolerance in which respect for differences is the main value, considering the human being as an absolute priority, whatever their age group. Also according to the author, the social groups where there is the presence of different generations can promote quality of life and the exercise of citizenship, reaching goals as socialization or re-socialization, upgrading knowledge, developing of new skills, reflections about the aging process, development of new life projects.

As for the learning process, participants report that the actions developed for teaching the use of technologies to the elderly are made easier due to the availability and commitment of these in learning, so the established relationship between them is quite natural. Toward monitors, the elderly are understandable and patient, in addition to accepting the role reversal, in which the young begin to teach the elders. In accord to Oliveira and Scortegagna (2009), elderly teach in any field of knowledge is recognized as a strong tool for improving the quality of life of this age group through the rescue of dignity, participation, citizenship, increased self-esteem, thus providing greater activity, participation and integration into society.

During the process of reciprocal exchange between different generations, transfers, as well as mutual teaching, are mediated by characteristics, resources, opportunities and needs of each generation (Camargos, Rodrigues, \& Machado, 2011).

In general, elderlies transmit models of behaviour, memories, life stories and cultural aspects, while the younger transmit values and behaviours of today and assist in the development of skills and abilities to the use of technological resources. The conviviality and the exchange of knowledge favours the adoption of more positive attitudes toward each other and avoids the compartmentalization of social spaces according to age group (Ferrigno, 2006). 
Regarding the benefits of the relationship established with the elderly while participating in the Project, the monitors report that these have influenced directly in their personal lives and in their family context, because they learned to be more patient, tolerant and respectful to the elderly at home, transferring the knowledge acquired to family relationships. This enabled closer relationships and the increase in daily contact time with older family members.

Currently it is common for families to be composed of three or more generations. The longevity phenomenon undoubtedly has a direct impact on family configuration bringing challenges related to support, co-education and mutual care among members of the same family, which despite having different characteristics and interests, work together in the pursuit of collective well-being (Herédia, Casara, \& Cortelletti, 2007).

Family intergenerational relationship is configured as a constant game of changes relating to the performance of roles and obligations among its components, mainly by behavioural variations that differ from one generation to another and are culturally and socially constructed. Despite the differences, different generations living together enable the reconstruction and renewal of mutual understanding. For this to be possible not only just the coexistence of these characters is important, but also the availability and acceptance in seeking peaceful relations and quality (Herédia, Casara, \& Cortelletti, 2007).

In response, the monitors also report that they began to help and teach family members in the use of electronic devices. Finally, after participating in the project they began to feel more mature and they noticed personal growth.

Today it is increasingly asserted that contact between different generations is extremely important and, it is a precious opportunity to acquire new knowledge and values of contemporary society (Ferrigno, 2006). The interaction between generations is a valuable tool to delete preconceptions, to the transfer of knowledge, mutual aid, solidarity and friendship.

\section{CONCLUSION}

Young people report that they were able to transfer what they have learned in the relationship with the elderly for their family environment reporting that they began to act with more patience and tolerance, and now have a closer interaction with elderly relatives, and better understand their difficulties and recognize their potential and they started to assist and teach family members in the use of electronic devices.

The intergenerational interaction is a valuable tool to exclude preconceptions, for the transfer of knowledge, mutual aid, solidarity and friendship ${ }^{3}$. In this study we note that young people recognize changes in their personal behaviour and in their interaction with their relatives, whether elderly or not, transferring the learning acquired through intergenerational relationships to their routine, as well as recognize that when teaching seniors how to use new technology they receive in exchange knowledge derived from rich and vast experience.

\section{ACKNOWLEDGMENT}

We would like to thank the Foundation for the Support of Teaching, Research and Service of the (FAEPA) - Clinical Hospital of Ribeirão Preto Medical School, University of Sao Paulo, the Pro-rector of Culture and university Extension University of Sao Paulo and the Difital Inclusion Project of Elderly people.

\section{REFERENCES}

[1] Holtz, C. (2008). Global health care: issues and policies. Sudbury: Jones \& Bartlett.

[2] IBGE - Brazilian Institute of Geography and Statistics (2015). National Survey by Household Sampling. Projection of Brazil's population by age and sex for the period 1980-2050: review. Rio de Janeiro. Recuperado de: http://www.ibge.gov.br/home/estatistica/populacao/projecao_da_populacao/2008/projecao.pdf

[3] Zanon, R. R., Moretto, A. C., Rodrigues, R. L. (2013). Population aging and changes in consumption patterns and in the Brazilian productive structure. Revista Brasileira de Estudos Populacionais, 30 (Suppl.), S45-S67.

[4] Schmidt, C. (2007). The relationship between grandparents and grandchildren: co-educational possibilities. (Dissertação de Mestrado). Universidade Federal do Rio Grande do Sul, Porto Alegre, RS.

[5] Souza, E. M. (2003). Intergenerational interaction in health promotion: a qualitative study in Brazil. Revista de Saúde Pública, 37(4), 463-9.

[6] Gvozd, R., Dellaroza, M. S. G. (2012). Old age and the relationship with the elderly: the look of teenagers from elementary school. Revista Brasileira de Geriatria e gerontologia, 15(2), 295-304.

[7] Neri, A. L. (1993). Quality of life and old age. Campinas: Papirus.

[8] Goldfarb, D. C., Lopes, R. C. G. (2006). Avosidade: the family and the psychic transmission between generations. In: Freitas E.V., PY, L., Cançado, F. A. X.; Doll, J.; Gorzoni, M. L., Tratado de Geriatria de Gerontologia (pp. 1374-1382). Rio de Janeiro: Guanabara Koogan.

[9] Ramos, M. P. (2002). Apoio social e saúde entre os idosos. Sociologias, 7, 156-175.

[10] Santana, C. S., Pereira, A. P. (2012). Perception of undergraduate students on academic practical activities with seniors: co-education of generations and vocational training. Diversa Prática, 1(1), 125- 134. 
[11] Ferrigno, J. C. (2006). The co-education between generations: a challenge of longevity. A terceira idade, 17(37), 1626.

[12] Oliveira, R. C. S., Scortegagna, P. A. (2009). Public policy, education and citizenship in old age. Anais do IX Congresso Nacional de Educação e III Encontro Sul Brasileiro de Psicopedagogia. Recuperado de:< http://www.pucpr.br/eventos/educere/educere2009/anais/pdf/2568_1053.pdf>

[13] Camargos, M. C. S., Rodrigues, R. N., Machado, C. J. (2011). Elderly, family and home: a narrative review of the decision to live alone. Revista Brasileira de Estudos Populacionais, 28(1), 217-230.

[14] Ferrigno, J. C. (2006). Social work with elderly: Presentation pioneering experience in SESC in the leisure and culture area. Cadernos de Terapia Ocupacional da UFScar, 14(1), 23-31.

[15] Herédia, V. B. M., Casara, M. B., Cortelletti, I. A. (2007). Longevity impact on multigenerational family. Revista Brasileira de Geriatria e Gerontologia, 10(1), 07-28.

\section{Author' biography with Photo}

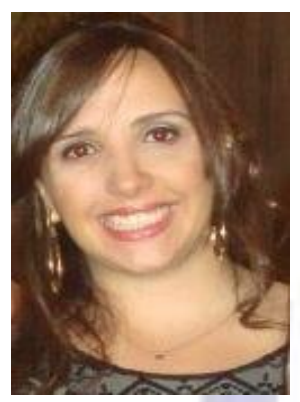

Taiuani Marquine Raymundo - Occupational Therapist, M.Sc. degree in Science Bioengineering area, Ph.D. student at the Post- Graduate program Interunits in the Bioengineering Area - Engineering School of Sao Carlos, Medical School of Ribeirao Preto, Institute of Chemistry of São Carlos, University of Sao Paulo, Brazil. Professor of Occupational Therapy in the Department of Occupational Therapy, Federal University of Parana.

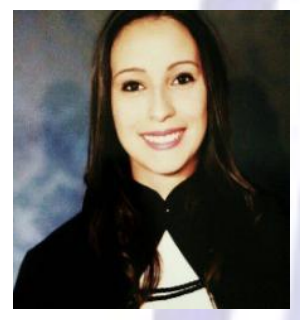

Marina Soares Bernardes - Occupational Therapist - Masters Student at the Post- Graduate program Interunits in the Bioengineering Area - Engineering School of Sao Carlos, Medical School of Ribeirao Preto, Institute of Chemistry of São Carlos, University of Sao Paulo, Brazil.

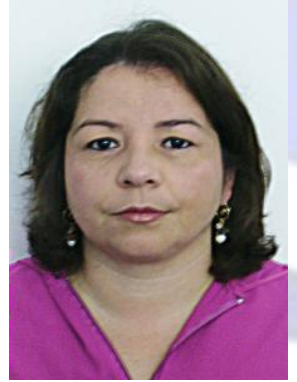

Carla da Silva Santana - Occupational Therapist, postdoctoral degree from the Oxford Institute of Population Ageing, University of Oxford. Professor of Occupational Therapy in the Department of Neuroscience and Behavior Science, Medical School of Ribeirao Preto, University of Sao Paulo. 